\title{
As finalidades dos sistemas de educação brasileiros
}

Antonio Chizzotti

Pontifícia Universidade Católica de São Paulo (Brasil)

\section{Resumo}

Este artigo analisa as finalidades da educação escolar. Os debates eleitorais expuseram, nas tensões da retórica, um conjunto discrepante de opiniões sobre as finalidades e as responsabilidades da educação escolar. Os discursos dos candidatos, dos educadores e dos pesquisadores e a participação de diferentes grupos sociais nas discussões sobre educação trouxeram para o espaço público a importância da educação escolar para a construção do projeto político do Estado brasileiro. Este trabalho sintetiza essas manifestações e faz uma análise bibliográfica das finalidades da educação para explicitar quais são as finalidades fundamentais dos sistemas de ensino nacionais. $\bigcirc$ artigo analisa as três finalidades prospectivas da educação definidas na Constituição Brasileira: o pleno desenvolvimento da pessoa, o preparo para o exercício da cidadania e a qualificação para o trabalho. São questões antigas, permanentes e sempre atuais nos sistemas nacionais de educação, historicamente fundamentais para construir-se um Estado e uma sociedade democrática, que garanta a Educação Básica universal para todos os brasileiros. Palavras-chave: Finalidades da educação. Desenvolvimento da pessoa. Cidadania. Trabalho.

\section{The purposes of the brazilian education systems}

\section{Abstract}

This paper analyses the aims of school education. The electoral debates exposed, in the tensions of rhetoric, a discrepant set of opinions about the purposes and responsibilities of school education. The speeches of candidates, educators and researchers and the participation of different social groups in discussions about education brought to the public space the importance of school education for the building of the political project of the Brazilian State. This research synthetizes these manifestations and makes a bibliographical analysis of the purposes of education to explain what are in-depth the fundamental aims of Basic Education of the national education systems. The article analyzes the three prospective goals of education defined in the Brazilian Constitution: the full development of the person, the preparation for the exercise of citizenship and the qualification for work. These are permanent and always current issues in national education systems, historically essential to be persecuted to build a democratic State and society that guarantees universal Basic Education for all Brazilians.

Keywords: Purposes of education. Development of the person. Citizenship. Work. 


\section{Las finalidades de los sistemas de educación brasileños}

\section{Resumen}

Este artículo analiza las finalidades de la educación escolar. Los debates electorales revelaron, en las tensiones de la retórica, un conjunto discrepante de opiniones sobre las finalidades y responsabilidades de la educación escolar. Los discursos de los candidatos, de los educadores y de los investigadores y la participación de diferentes grupos sociales en las discusiones sobre educación trajeron al espacio público la importancia de la educación escolar para la construcción del proyecto políitico del Estado brasileño. Esta investigación sintetiza esas manifestaciones y realiza un análisis bibliográfico de las finalidades de la educación para explicar cuáles son las finalidades fundamentales de los sistemas de enseñanza nacionales. El artículo analiza las tres finalidades prospectivas de la educación definidas en la Constitución Brasileña: el pleno desarrollo de la persona, la preparación para el ejercicio de la ciudadanía y la calificación para el trabajo. Son cuestiones antiguas, permanentes y siempre actuales en los sistemas nacionales de educación, históricamente fundamentales para construir un Estado y una sociedad democrática, que garantice la Educación Básica universal para todos los brasileños.

Palabras clave: Finalidades de la educación. Desarrollo de la persona. Ciudadanía. Trabajo.

\section{Introdução}

As discussões atuais sobre as finalidades da educação traduzem a crise e os dilemas dos sistemas de educação, forçados a responder às novas exigências sociais e culturais dos cidadãos. $\bigcirc$ processo eleitoral, em 2018 , trouxe para a disputa política uma profusão múltipla de expectativas e manifestações públicas sobre a educação nacional, ingenuamente responsabilizada pelo insucesso na solução de problemas estruturais da sociedade ou pelo baixo resultado educacional, se comparada aos níveis internacionais de qualidade.

Essas manifestações revelaram no cenário eleitoral uma inflação de propostas saneadoras, sequestrada pelos grupos políticos e confiscada pela retórica partidária; muitas delas, idealizações ingênuas de autores solitários ou proposições aleatórias de candidatos noviços. Estes, insuflados por meios mediáticos, propunham medidas coercitivas a qualquer processo de ensino, a fim de coibir fantasiosos riscos da educação pública e, no final, advogavam objetivos imaginários sobre a natureza e a missão da educação escolar.

Os discursos políticos ordinários sempre tendem, no fragor polêmico dos argumentos, deslocar as finalidades da educação para questões decorrentes de decisões técnicas e administrativas, de erros dos adversários ou de um passado mitificado, derivando para questões muito distantes das realidades 
vividas pelos alunos e pelos professores no cotidiano da educação. Esses debates evidenciaram uma exuberância de propostas, apoiadas por diferentes grupos, cada qual com algumas proposições aleatórias; outras, fantasiosas, e, no geral, com objetivos impertinentes e contraditórios sobre as finalidades possíveis da educação escolar.

Nessa discussão acalorada, as pessoas e o público, em geral, presumem, também, saber e opinar sobre educação, apoiadas na experiência pessoal, adquirida no meio familiar, escolar, social e profissional. Reconhecem o valor e a importância da educação e consideram que estão habilitadas para, de sua experiência pessoal, solucionar os problemas que decorram da "falta de educação". É um tema que provoca muitas opiniões e gera polêmicas e partidos sobre os meios saneadores da educação nacional. Nos períodos eleitorais, o tema adquire vivacidade singular e debates flamejantes, como ocorreu na disputa eleitoral.

Por um lado, a flagrância das questões recrutou, também, para o debate, instituições, grupos, movimentos diversos e personalidades aguerridas e controversas, todos interessados em representar projetos e programas de ensino, alguns consistentes; muitos, fantasiosos e até bizarros. Essas declarações eleitorais evidenciaram, por outro lado, a relevância social e a importância política da educação escolar. Os discursos trouxeram, para o espaço público, o reconhecimento histórico da sociedade pela educação escolar, atravessada por demandas sociais e expectativas difusas sobre finalidades possíveis da educação.

processo eleitoral trouxe, também, o debate público sobre as finalidades da educação escolar brasileira. Em contraposição ao ambiente de falas ruidosas, movimentos sociais, educadores e grupos de pesquisadores, com apoio de instituições públicas e privadas, ingressaram no debate, mobilizaram-se, interessados em trazer, ao debate, agitado por manifestações, polêmicas e diálogos conturbados, uma contribuição para elevar o nível aberrante dos discursos e incluir a relevância da educação no projeto político do Estado.

As providências do governo, que se sucederam, após a eleição, foram constrangedoras ao veicular proposições incriminadoras à escola como lugar de suspeição ética, conspirando contra os ideais da nação e, até, da civilização ocidental, e urgindo a vigilância policial do ensino contra uma potencial delinquência ideológica do magistério e o risco de perversão ética e 
disciplinar dos discentes. Assim, após a posse do novo governo, seus próceres difundiram narrativas depreciativas da educação e aviltantes aos educadores, secundadas por uma retórica populista, que conflagraram ruidosamente os debates, polarizados por um clima de hostilidade incomum, envolvendo muitos segmentos da sociedade. Foram tão virulentas as alocuções ideológicas que derivaram para propostas de militarização das escolas e inclusão de militares na docência escolar pública, sob o pretexto de salvaguardar a disciplina e a integridade moral da educação escolar. Para atender a esse projeto, o Decreto no 10.004/2009, de 5 de setembro de 2019, criou o Programa Nacional das Escolas Cívico-Militares (Pecim) e instituiu as Escolas Cívico-Militares-Ecim (BRASIL, 2019).

As primeiras providências do âmbito do Ministério da Educação foram, também, tão erráticas que moveram seis ex-ministros da educação de quatro ex-presidentes diferentes, José Goldenberg, Murílio Hingel, Cristovam Buarque, Fernando Haddad, Aloizio Mercadante e Renato Janine a divulgarem carta conjunta em defesa da educação nacional, ameaçada por providências aberrantes do novo governo.

As famílias e o público, em geral, partilharam, e ainda partilham, dessas disputas, pois esperam uma orientação contributiva da escola sobre os mais diversos problemas e se decepcionam quando não encontram a solução às suas expectativas, saídas da escola, local considerado confiável e apto para resolver os mais diversos problemas. As famílias têm, em geral, um grande apreço pela escola: reconhecem como um local de grande valia na construção da família e de formação aprimorada de seus filhos. Contudo, sentem o temor de que seus filhos não sejam reconhecidos e bem aceitos, em virtude das condições econômicas precárias da família ou de alguma limitação particular desse aluno. As aspirações e os temores particulares das famílias e as consuetudinárias injunções político-partidárias acabam turbando as finalidades efetivas da educação escolar.

Essas expectativas encontram eco em agentes políticos que, desejosos de dar uma contribuição aos problemas sociais, remetem à educação escolar a obrigatoriedade de inserir temas curriculares para sanar problemas sociais. Essas expectativas e propostas, ainda que bem-intencionadas, se traduzidas em programas de ensino, podem sobrepor muitas atividades aleatórias, que deixam confusas as finalidades precípuas da educação escolar. 


\section{Debate nacional: extensão do debate internacional}

debate nacional sobre as finalidades da educação escolar atualizou, no âmbito local, a crise mundial da escola, atravessada por muitas interrogações, trazidas pelas transformações econômicas, políticas e culturais, provocadas pela globalização, portadora de frustradas esperanças com a mercantilização da vida, pelo desenvolvimento do capitalismo, progressivamente desigual, pelas novas tecnologias da informação e comunicação, ainda seletivas e excludentes, pela massificação do ensino, desiguale elitista. E, mais recentemente, as grandes mudanças que transformam a educação, nesse final de década; o deslocamento do centro de gravidade mundial, a coisa pública, a segurança em um mundo exposto, viver melhor e viver mais, e as novas culturas modernas (OCDE, 2019), questões que afetam os sistemas de educação e suscitam interrogações sobre as suas reais finalidades, pois todos os estados democráticos conhecem o impacto social da educação e seus efeitos sociais, cumulativos e interativos, em todos os domínios da vida, tanto para a vida do indivíduo-cidadão, quanto para o conjunto da sociedade. $\bigcirc$ debate internacional sobre a escola adentrou, desse modo, o discurso local e atualizou os acordos e as dissensões sobre as finalidades e as possibilidades atuais da educação nos estados democráticos em todo o mundo.

A construção de sociedades mais justas constitui objetivo central do projeto político do Estado nacional. Nesse sentido, a educação é condição necessária inderrogável desse projeto do imaginário político democrático, ainda que haja desconfiança ou ceticismo sobre a possibilidade efetiva dos governos realizarem esse desafio.

Um panorama mundial das exigências educacionais tradicionais dos sistemas nacionais de educação revela que, além das finalidades preconizadas explicitamente pelo Estado, muitas outras finalidades têm sido privilegiadas por outros grupos, instituições, partidos políticos, a fim de atendera aspirações específicas de grupos particulares e territórios regionais. Em síntese, os sistemas de educação foram profundamente convulsionados pelas novas exigências sociais e culturais. Tornaram-se objetos de críticas e proposições sobre as muitas orientações e atividades da escola, que revelam a sobreposição de projetos governamentais, uma difusão de objetivos e a ausência de consensos sobre as finalidades atuais da educação escolar. 


\section{O valor da educação escolar nos tempos atuais}

Neste momento histórico da educação brasileira, é preciso uma atuação consistente de todo magistério e de setores sociais na defesa das finalidades da educação para que a escola cumpra sua missão política e cultural. Para isso, é preciso especificar e ter presente, clara e objetivamente, as finalidades do sistema de educação, pois, no debate político ordinário, as finalidades ficam obscurecidas pela inclusão de muitos temas polêmicos periféricos e pela sobreposição indefinida de prioridades que conturbam os debates e deixam ofuscadas as finalidades do sistema de educação. São, também, muitas as opiniões que requerem da educação escolar a solução de muitos entraves que acontecem no espaço público da sociedade, tais como, a ecologia, o reforço da democracia, a equidade econômica, a igualdade social, entre outros. Todas essas questões são relevantes e estão no horizonte de toda a educação, mas exorbitam o alcance imediato de seu sistema.

Os desacordos ideológicos e políticos tornam indispensável a urgência de aprofundar o objetivo histórico da educação escolar e as exigências novas que se impõem, atualmente, aos sistemas de educação nacional. Urge,

6 pois, superar o ambiente de disputas iracundas e restaurar a importância e a confiança na educação escolar como um centro promotor pessoal de cada indivíduo-cidadão e como polo difusor da cultura e dos valores que dão suporte à vida social e promovem a elevação econômica, política e cultural de toda a sociedade. A educação escolar e suas finalidades históricas e sociais estão, pois, no centro dos desafios que a sociedade brasileira enfrenta e deve resolver, ainda que suportem muitas contradições, derivadas das condições objetivas da sociedade na qual está inserida. Desse modo, o reconhecimento público e a consideração histórica da sociedade sobre a importância da escola e do trabalho dos professores podem gerar uma multiplicidade de expectativas em torno da solução das questões emergentes da vida cotidiana.

Todos os que se dedicam à educação escolar devem ter claras as finalidades do processo educativo para não sobrepor uma justaposição indistinta de objetivos e de atividades aleatórias que confundem o processo de aprendizagem, deixam os alunos perplexos, frustram os professores e desorganizam o projeto político e pedagógico da educação escolar. Os professores e a gestão da escola tendem a dispender muito mais energia e tempo no cumprimento de uma superposição de obrigações burocráticas apensadas à 
atividade pedagógica, como micro ações administrativas, constantes e urgentes, que fragmentam o ensino e obscurecem ou ocultam as finalidades efetivas da educação escolar.

\section{As finalidades da educação na Constituição Brasileira}

A Constituição Brasileira de 1988, na esteira de muitos outros sistemas da educação pública, estabeleceu as finalidades efetivas, não derrogadas até o presente, da educação escolar. Essas finalidades estão presentes em quase todos os sistemas públicos de educação, porém são muitos e numerosos outros objetivos preconizados por governos, privilegiados por partidos políticos no poder ou por instituições e grupos sociais, que se sobrepõem às finalidades da educação e podem gerar um acúmulo indistinto e embaralhado das finalidades efetivas dos sistemas de educação.

A Constituição Brasileira, no título VIII, da Ordem Social, no Capítulo III, Seção I - Da Educação, no artigo 205, explicita as finalidades da educação pública:

Art. 205. A educação, direito de todos e dever do Estado e da família, será promovida e incentivada com a colaboração da sociedade, visando ao pleno desenvolvimento da pessoa, seu preparo para o exercício da cidadania e sua qualificação para o trabalho (BRASIL, 2018, p. 160).

\section{O direito de todos e o dever do Estado}

artigo constitucional é enfático em professar a concepção republicana do sistema de educação e formalizar as três finalidades prospectivas fundamentais da educação escolar: o pleno desenvolvimento da pessoa, seu preparo para o exercício da cidadania e sua qualificação para o trabalho. Essa concepção manifesta e centraliza obrigatoriedade do Estado em garantir, e os cidadãos acatarem, o quê, a quem e para que deve ser ensinado na educação escolar.

sistema de educação republicano, resultado histórico da formação do estado-nação, gerado nos muitos conflitos e consensos que deram uma nova 
forma aos estados centro-europeus, no século 17 e 18, e, no mundo moderno, consolidou-se como uma organização democrática na qual os indivíduos se tornam cidadãos - uma república, declarada formalmente e considerada juridicamente, formada por membros iguais em direitos, seres políticos independentes, personalidades livres e autônomas. Uma das instâncias relevantes na garantia da unidade nacional e de formação de personalidades iguais e livres é a educação de toda a população no mesmo espírito e consonância de vida e de valores comuns.

A educação pública escolar tornou-se, e assim se consolidou no século passado, como obrigação fundamental do Estado moderno que deve elaborar e oferecer, no âmbito nacional, programas escolares detalhados para cada nível de ensino para dar a mesma educação para todos os cidadãos, indistintamente, a fim de garantir a igualdade dos direitos e a equidade das oportunidades. A educação oferecida pelo Estado republicano consolidou-se, no decurso do século passado, como uma organização, progressivamente, centralizada dos conteúdos do ensino para garantir iguais direitos e chances a toda a comunidade de cidadãos. O resultado histórico desse processo é a centralização da educação no poder executivo que, pelas suas instâncias

8 administrativas ministeriais, é quem determina os conteúdos e as instruções executivas do ensino.

A educação e todo o sistema de ensino escolar, nos estados democráticos, estão no centro de um projeto político universalista da educação: todos os indivíduos, elevados à condição de cidadãos, têm, indistintamente, o direito subjetivo à educação escolar, e o Estado tem obrigação objetiva de garantir a todos os cidadãos a igualdade de direitos civis e sociais dos quais a educação escolar é parte substantiva.

Esse programa universalista significa que não pode haver exceções a esse direito por causas externas ao indivíduo-cidadão, tais como: a falta de escola, de professor, de equipamento, de transporte, de recursos financeiros ou de gestão administrativa, nem por causa de condições particulares do indivíduo, como limitações físicas, locomotoras, ou particularidades corporais, mentais, ou legais, como o aprisionamento.

É obrigação pública e indissociável do Estado democrático moderno educar todos os membros do Estado para a aquisição dos bens culturais e sociais, indispensáveis à realização pessoal e social de todo cidadão. Essa 
participação comum tornou-se uma tarefa fundamental do Estado moderno republicano, considerada a forma mais acabada de organização política. Compete a ele a responsabilidade primeira da educação, porque um Estado democrático é considerado, também, o meio mais seguro de formar uma comunidade humana, composta de cidadãos livres e autônomos, fundamento imprescindível da liberdade humana dos cidadãos e de toda a sociedade civil.

princípio fundador da unidade nacional republicana é a partilha comum nas ideias e a adesão em torno dos direitos fundamentais de todos os cidadãos e na garantia de uma unidade de convicções, fundamentadas na racionalidade do Estado, na organização econômica e na partilha de uma homogeneidade cultural, que consolide o assentimento coletivo nos conhecimentos básicos de convívio, no reconhecimento da herança cultural, na memória coletiva dos feitos e mitos que fizeram a nação e nos conhecimentos fundamentais dos meios de convivência e trocas de bens e de serviços.

Incumbe ao Estado integrar toda a população em uma comunidade de cidadãos e garantir instituições que de em suporte à democracia. A escola é um dos fundamentos dessa vida democrática pela função primordial de transmitir e conservar a cultura nacional, resguardar as tradições históricas do passado originário da nação, dar os meios de garantir sua unidade no presente e no futuro. Esse saber torna o Estado a instância responsável para que cada indivíduo, livre da ignorância dos meios disponíveis para realizar sua vida e ciente dos liames sociais, seja um indivíduo-cidadão, responsável por si e pelos outros, emancipado dos constrangimentos políticos, livre e autônomo para realizar seu projeto de vida com a garantia do Estado.

Estado republicano pressupõe uma forte centralização do que os alunos devem aprender e os professores, ensinar, como garantia da igualdade de direitos de cada cidadão ter os mesmos conteúdos de ensino e iguais chances sociais, cabendo, portanto ao executivo, por meio de suas instâncias ministeriais e demais órgãos burocráticos de gestão pública, definir, acompanhar e avaliar o que deve ser ensinado. Para isso, o Estado deve elaborar uma base comum de conhecimentos, atitudes e responsabilidades, indispensáveis a todo cidadão e a toda a sociedade, prescrito nacionalmente e coordenado pelas instâncias administrativas do Estado nos âmbitos nacional, estadual e municipal, como garantir da igualdade de chances e de oportunidades educacionais, culturais e políticas. O pressuposto é que seja igual tanto 
a oportunidade de estar na escola, quanto a oferta do mesmo conteúdo do ensino, afim de que todos alcancem os mesmos resultados.

Estado democrático pressupõe uma escola democrática: uma escola que deve dar a todos as capacidades intelectuais e éticas necessárias para se formar, como pessoa-cidadã e participar da vida pública (SHNAPPER, 1994; SHNAPPER; BACHELIER, 2000). Historicamente, a cidadania compôs três paradigmas: um, voltado à obediência às leis e ao respeito aos deveres, como voto, imposto e serviço militar e pertença à comunidade política nacional; outro, centrado no indivíduo - em sua liberdade e responsabilidade nas diversas formas de presença na sociedade, e, no contexto atual, uma cidadania crítica e uma competência para envolver-se nos debates da democracia (AUDIGIER; FILLION 2012 ; AUDIGIER, 2015, 2018).

\section{Igualdade formal de direitos e desigualdade social}

Uma questão relevante no Estado republicano é como conciliar a igualdade formal comum de direitos e de cultura comum com a desigualdade 10 econômica e social; em outras palavras, como garantir, aos membros da sociedade, em um Estado unido em que os membros participam, formalmente, dos direitos políticos, a produção econômica e a vida cultural, mas tendo uma estrutura social desigual.

A proclamação jurídica da igualdade formal dos direitos dos cidadãos não elide a estrutura social do Estado. A escola, pois, não está isenta, nem imune ao seu contexto social. Ela depende das condições econômicas e políticas do Estado no qual está inserida. Essas condições são determinantes para alcançar ou limitar o alcance das finalidades, constitucionalmente expressas do sistema de educação.

As desigualdades estruturais, econômicas e sociais do Estado que se afirma democrático tendem a subsistir na educação escolar, apesar do grande esforço equalizador que a educação escolar promove. Além disso, o fundamento igualitário está alicerçado no princípio meritocrático: as chances de cada um dependem de seus méritos individuais, expressos sistematicamente por meio das avaliações de seus resultados escolares.

Este fundamento implícito da igualdade legal - dar a cada um segundo suas capacidades e seus méritos pessoais - gera uma surda e desigual 
concorrência entre os alunos e instaura um processo, pretensamente neutro, uniforme e imparcial, de avaliação meritocrática, pela qual, sob a égide dos méritos individuais de cada um, provoca a seleção de uma elite, daqueles que são considerados melhores pelas suas condições econômicas e sociais, com a finalidade de organizar a distribuição meritocrática das posições sociais e, em contraposição, relega os restantes sob pretexto de carências intelectuais particulares (FRANCE STRATÉGIE, 2016). A igualdade legal escolar, pois, não desfaz a reprodução das relações de produção da sociedade e, no Estado moderno capitalista, essas relações estão presentes na organização da escolaridade universal de todos os cidadãos.

Desse modo, apesar da grande contribuição que a escola oferece para elevar as condições sociais do conjunto da sociedade, ela é conformada pelas condições objetivas do Estado no qual está inserida, reestruturando no interior da escola as desigualdades econômicas e sociais do Estado. Assim, a produção e a distribuição justa dos bens produzidos e partilhados na vida econômica e cultural são decisivas para o alcance das finalidades igualitárias, que a educação escolar almeja, mas ficam comprometidas pelas desigualdades das relações de produção econômicas.

\section{Educação: dever do Estado e da família}

A Educação Básica, que ofereça as condições fundamentais de vida solidária, torna-se obrigatória para todos os cidadãos. A família é sempre o lugar do aprendizado fundamental, mas ela não dispõe de meios materiais, culturais e sociais que a educação escolar oferece. Por isso, os sistemas democráticos tornam obrigatória a Educação Básica escolar de seus cidadãos.

sistema de ensino universalista- a todos os cidadãos - pressupõe uma centralização do que deve ser ensinado a todos, indistintamente, como garantia de direitos a todos os cidadãos da nação ao afirmar "a todos, indistintamente". Esse princípio forjado no período iluminista, pré-capitalista, supõe uma fraternidade política idealizada, sem diferenças econômicas e sociais. O dilema dos estados democráticos é garantir que a cidadania não seja um direito abstrato, fora das condições econômicas e sociais dos cidadãos. 
A Constituição avaliza três finalidades fundamentais prospectivas para a educação escolar: o pleno desenvolvimento da pessoa, o preparo para o exercício da cidadania e a qualificação para o trabalho.

\section{Primeira finalidade: o pleno desenvolvimento da pessoa}

A primeira finalidade da educação escolar nos sistemas de educação dos estados nacionais republicanos, expressa na Constituição Brasileira, é o pleno desenvolvimento da pessoa. A escola deve propiciar a realização da personalidade de cada aluno: o desenvolvimento de suas aspirações, talentos e virtualidades pessoais, capacitando cada cidadão para realizar sua vida conforme seus interesses no convívio de seus concidadãos. $\bigcirc$ pressuposto fundamental da aprendizagem escolar é o impacto profundo que a educação gera em todos os domínios da vida, e ao longo de toda a vida, qualquer que seja a idade, tanto na vida privada em suas relações interpessoais, quanto na sua vida social em suas interações sociais.

Desse modo, é direito de cada aluno construir um percurso de aprendi-

12 zagem, prospectivamente singular e único, que lhe dê as condições necessárias para elevar a qualidade de sua vida e alcançar sua realização pessoal, atual e futura. Essa qualidade de vida não pode ser, somente, futurível; deve começar, de modo incoativo, no tempo de vida na escola. Não é possível o aluno desejar aprender, adequadamente, e desenvolver-se, intelectual e socialmente, sem acreditar nele próprio ou sendo infeliz na escola, pois o longo tempo da vida na escola não pode limitar-se a transmitir saberes; deve, também, ser um tempo em que se sinta feliz e reconhecido pelas suas aspirações e pelos seus limites, aprendendo as exigências que se deve fazer para garantir a formação de sua personalidade e sua inclusão no convívio social.

A formação da personalidade livre e emancipada impõe um alto grau de disciplina e de exigências pessoais, e o professor é, e deve ser sempre, um guia benevolente para auxiliar cada aluno a alcançar seu autodesenvolvimento pessoal, sendo responsável tanto pelos seus atos e pelas suas escolhas pessoais, quanto pelo reconhecimento de seus próprios limites. Requer, pois, atender, sobretudo, às aptidões de cada um pelo que sabe fazer e não pelas suas carências pessoais e, muito menos ainda, partir de exigências externas prefixadas, sem consideração aos horizontes particulares de cada um. 
A formação da personalidade emancipada pressupõe que venha ser alguém que saiba desenvolver os elos interpessoais com os outros, superando o isolamento afetivo e social, para agir de modo socialmente responsável e interagir de modo construtivo com os outros. $\bigcirc$ autoconhecimento é parte indispensável de sua formação: o reconhecimento de sua identidade pessoal, de sua revelação social no contexto escolar e de sua afirmação humana no convívio diversificado do público escolar é fundamental para sua identidade humana e sua inserção na vida social. $\bigcirc$ autoconhecimento não significa que o aluno já sabe tudo o que precisa saber, mas supõe partir de cada singularidade para identificar o que a escola deve ensiná-lo, acompanhando cada aluno em seu percurso de aprendizagem, presumidamente único, a fim de que o aluno possa ir mais longe, quanto possível, em seu projeto de vida.

A formação de uma personalidade, historicamente situada no contexto de um estado concreto, pressupõe a consciência da orientação política do Estado ou dos governos, que são determinantes na formação do indivíduo-cidadão. Nos estados democráticos, a formação da personalidade visa preparar cada um para interagir, construtivamente, na coexistência harmoniosa entre as pessoas, seja no convívio cotidiano com outras pessoas, seja na participação eficaz nas comunidades locais, regionais ou nacionais das quais faz parte.

\section{Segunda finalidade da educação: o preparo para o exercício da cidadania}

A segunda finalidade fundamental da educação é a preparação para o exercício da cidadania, consequência lógica da formação da personalidade, pois o desenvolvimento da personalidade do indivíduo-cidadão só é possível se ele for capaz de conviver, solidariamente, com seus concidadãos e estar apto para construir e preservar os laços afetivos e sociais que unem uns aos outros, seus colegas, sua família e seus concidadãos. Em suma: a socialização é essencial na construção da personalidade. A formação cívica e a educação nos direitos humanos são missões antigas, com problemas permanentes, e um projeto sempre atual nos estados modernos, passível de diferentes ideais-tipos de cidadania nos estados nacionais e globalizado (RAVEZ, 2018). 
A educação para a cidadania é uma noção vasta e fluida, varia segundo o tempo e o espaço, pois

[...] fatores como o tipo de constituição políitica, o nível da riqueza econômica, o grau de estabilidade políitica, a coesão nacional e as relações internacionais pacíficas exercem forte influência na definição oficial do conteúdo das competências mais pertinentes e úteis para os cidadãos (COMMISSION EUROPÉENNE, 2017, p. 19).

A cidadania é um direito, juridicamente garantido a todos os indivíduos, membros do Estado, que atribui ao indivíduo-cidadão os direitos civis, sociais e políticos para participar da vida econômica, política e social, e ser candidato às funções públicas, tendo, em contrapartida, a obrigação de respeitar as leis, contribuir para as despesas coletivas e defender a sociedade da qual é membro. Compreende, pois, o cultivo do sentimento de pertença a uma comunidade de cidadãos e o compromisso de promover a coexistência harmoniosa e o desenvolvimento mútuo das pessoas e das comunidades das quais faz parte. A cidadania não se confina ao conjunto de direitos legais de liberdades políticas, fundamentado nos liames jurídico-políticos de um Estado abstrato, ela pressupõe a partilha e o usufruto dos valores e a garantia dos benefícios sociais disponíveis para toda a sociedade, como saúde, educação, segurança, proteção social.

preparo para o exercício da cidadania no Estado democrático visa integrar toda a população em uma comunidade de cidadãos e dar a todos a capacidade intelectual e social necessária para participar da vida pública: exercer direitos e cumprir obrigações para garantir o convívio solidário com outros membros da sociedade, composta por indivíduos, também livres e iguais, emancipados de todo poder arbitrário e com autonomia pessoal para se conduzir conscientemente na vida coletiva, participando dessa comunidade por laços de solidariedade e identidade na cultura nacional.

A formação dessa identidade nacional requer a conservação e a transmissão da cultura comum e impõe ao Estado a necessidade de determinar os conhecimentos e saberes indispensável a todos os alunos para que possam se tornar cidadãos conscientes da vida comum e participantes da vida pública. Os sistemas de educação têm essa finalidade fundamental de formação de indivíduos-cidadãos, ou seja, propiciar o desenvolvimento integral do 
ser humano, autônomo, responsável, apto para agir na sociedade de modo crítico, refletido, fonte da emancipação humana de cada membro do Estado. $\bigcirc$ princípio unificador do consentimento coletivo da população é a cultura comum, composta pelos conhecimentos, pelas crenças, pelas práticas, pelas leis, pelos costumes, pelas artes e pelas tradições e pelo modo de vida, criados, conservados e partilhados pelo conjunto da população do Estado nacional.

A transmissão do cabedal de vida social comum é uma das finalidades básicas da educação escolar. Ela deve ser, formalmente, prevista e prescrita para os currículos para todas as escolas, como vestíbulo de toda vida social a fim de cimentar a convivência mútua e responsável. A cultura comum, promovida pela educação escolar, é garantir a consolidação de uma sociedade política, liberta das consequências da ignorância intelectual e social dos próprios direitos e deveres individuais e de toda forma de servidão, derivada dessa ignorância, a fim de garantir a consolidação de uma sociedade democrática justa e solidária.

Estado republicano pressupõe, pois, a obrigação legal e política de dar a todos, em iguais condições, o direito de aprender como pressuposto necessário da igualdade de direito e equidade de oportunidades. No entanto, o processo de inclusão na educação e cidadania ativa ainda permanece como uma promessa não cumprida em muitos estados democráticos. A inclusão na cidadania não pode ser efetiva se a estrutura social não garantir a equânime partilha nos bens materiais produzidos pelo conjunto da sociedade, visto que a escola e a educação escolar não estão fora do seu contexto social. Dependem, necessariamente, dessas condições estruturais, econômicas e sociais do Estado no qual está inserida. Essas condições, muito além da proclamação formal da igualdade, são determinantes para realizar ou limitar o alcance das finalidades, constitucionalmente expressas, do sistema de educação.

Desse modo, as desigualdades estruturais, econômicas e sociais do Estado, que se proclama democrático, tendem a subsistir na educação escolar e conformar os alunos nos parâmetros dessa desigualdade estrutural, apesar do grande esforço equalizador que a educação escolar promove. Assim, a grande contribuição que a escola oferece para elevar as condições sociais do conjunto da sociedade está conformada pelas condições objetivas do Estado no qual está inserida. Desse modo, a produção e a distribuição justa dos bens produzidos e partilhados na vida econômica e cultural são decisivas para o alcance das finalidades equalizadoras que a educação promete. 
Avaliações comparativas internacionais podem, pois, estar radicalmente equivocadas quando pretendem comparar resultados escolares, sem ter em consideração as realidades econômicas e sociais de estados muito diferentes. A retórica da estratégia universal de controle e de modernização homogeneizadora dos sistemas de educação, por meio de avaliações comparativas internacionais, incidem em um ilusório equívoco ao dispensar a consideração da situação econômica e social de realidades muito diferentes.

\section{Terceira finalidade da educação: a qualificação para o trabalho}

desenvolvimento pessoal supõe uma trajetória de educação que leve o aluno a conseguir, na vida adulta, um lugar de trabalho ou um ofício, mas não é plausível partir de ofícios atuais ou idealizações futuras de trabatho para definir o que deve aprender hoje, mas pressupõe que o percurso, potencialmente único do aluno, o levará a construir um projeto de vida que the possibilite, no futuro, sustentar-se com seu trabalho, pois a inclusão na comunidade dos cidadãos requer que cada um possa, mediante um emprego estável, 16 contribuir para a produção de bens e de serviços para benefício de toda a sociedade, e ele próprio possa suprir suas necessidades fundamentais de consumo e de qualidade de vida.

A educação escolar tem lugar importante no pleno desenvolvimento da personalidade política de cada cidadão e no desenvolvimento de toda a sociedade, uma vez que, graças à educação escolar, o cidadão adquire um conjunto de saberes e competências que irão permitir melhor contribuir para sua própria realização e colaborar na construção de uma sociedade mais justa e solidária. Quanto melhor a educação escolar contribuir para a realização das aspirações pessoais e sociais de cada aluno, melhor poderá contribuir para assegurar a integração de cada cidadão na vida social e no trabalho, e, assim, maior será a consistência política e social do Estado.

A inclusão na comunidade dos cidadãos pressupõe que cada um possa partilhar da produção e suprir suas necessidades fundamentais de consumo, por meio de um emprego estável. Estar excluído do processo produtivo, sem poder adquirir os meios próprios de subsistência, não é um incidente circunstancial, é uma exclusão que desqualifica o direito de todo cidadão. $\bigcirc$ emprego é o fundamento da dignidade do cidadão e the confere o estatuto 
social com maiores chances de inserção social, de usufruir das trocas de bens materiais e culturais e realizar-se como participante da produção riqueza do Estado e pela justa redistribuição da riqueza produzida. Um dos fatores preponderantes do liame social é a participação no trabalho e na justa troca de bens e de serviços na vida econômica e social.

horizonte futuro da educação é preparar cada cidadão para que possa ocupar um posto de trabalho ou exercer uma atividade por sua própria conta. O trabalho, objetivamente, é tanto uma aspiração individual quanto uma atividade necessária, e até obrigatória, para encontrar os meios de vida e contribuir com o conjunto da produção dos bens necessários à vida coletiva; é, também, um meio que motiva, subjetivamente, o investimento individual na própria formação para um trabalho futuro e por meio do qual mantém contato com os outros e realiza o senso de pertença e partilha da vida em sociedade, contribuindo com seus esforços para a realização de si, de sua família e de toda a sociedade.

\section{Considerações finais}

As finalidades da educação escolar não podem ser dissipadas pelos discursos mirabolantes de pretensos mágicos, arvorados em redentores do país, judicantes do trabalho docente, e que se fazem, por autoproclamação delirante, salvadores iluminados da educação nacional. Essa retórica, difundida no período eleitoral e animada por grupos e sítios da internet, traz grande equívoco de avaliação do processo educativo e um sério desconforto aos que trabalham no campo da educação, pois tende a desagregar os esforços coletivos, arruinar os projetos políticos educacionais e comprometer as finalidades da educação.

A educação escolar continua sendo um campo de contradição permanente entre projetos políticos e projetos de vida. No atual período histórico da educação nacional e internacional, a educação, em todos os níveis e modalidades, mas, sobretudo, a relevância da Educação Básica, exige de todos os educadores, em qualquer instância de atuação, o empenho na construção da vida social nacional e, sem ilusões fantasiosas ou tensões circunstanciais da vida política, trabalhar pela concretização das finalidades históricas e sociais da educação nacional. 
A reafirmação constitucional das finalidades da educação escolar: o pleno desenvolvimento da pessoa, o preparo para o exercício da cidadania e a qualificação para o trabalho é um programa histórico da educação escolar. Constitui, ainda hoje, o programa indeclinável de todo sistema nacional de educação.

\section{Referências}

AUDIGIER, François. Éducation ‘a... et préparations à la vie. In: AUDIGIER, François; SGARD, Anne; TUTIAUX-GUILLON, Nicole (Org.). Sciences de la nature et de la societé dans une école en mutation. Fragmentations, recompositions et nouvelles alliances?. Louvain-la-Neuve: De Boeck, 2015.

AUDIGIER, François. L'esprit critique et enseignement de l'histoire: quelles pratiques pour quelles fins? In: ÉTIER, Marc-André; LEFRANCCOIS, David; AUDIGER, François (Org.). Pensée critique, enseignement de l'histoire et de la citoyenneté. Louvain-la Neuve: De Boeck, 2018.

18 AUDIGIER, François; FILLION

BRASIL. [Constituição (1988). Constituição da República Federativa do Brasil. Brasília: Supremo Tribunal Federal, Secretaria de Documentação, 2018. (Atualizada até a EC n. 99/2017).

BRASIL. Decreto No 10.004, de 5 de setembro de2019. Institui o Programa Nacional das Escolas Cívico-Militares. Diário Oficial [da] União, Poder Executivo, Brasília, DF, 6 de setembro de 2019. seção 1, p. 1-3.

COMMISSION EUROPÉENNE. L'éducation à la citoyenneté à l'école en Europe-2017. Rapport Eurydice. Luxembourg: Office des publications da l' Union européenne. Disponível em: hitp://publications.europa.eu/resource/cellar/6b50c5b0-d65 1-1 1 e7-a506-0 1 aa75ed7la1.0003.01/DOC_1. Acesso em: 5 set. 2019.

FRANCE STRATÉGIE. Quelle éducation pour quelle école. Disponível em: www.strategie. gouv.fr/.2016. Acesso: 2 set.2019.

$O C D E$. Les grandes mutations que transforment l'éducation 2019. Paris: Éditions OCDE, 2019. Disponível em: http//dx.doi.org/10.1787/trends_edu-2019-fr. Acesso em: 20 ago. 2019. 
RAVEZ, Claire. Regards sur la citoyenneté à l'école. Dossier de la veille de l'IFÉ, n. 125, juin. Lyon: ENS de Lyon, 1918. Disponível em:http://veille-et-analyses.ens-lyon.fr/DA/detailsDossier. php?parent=accueil\&dossier=1 25\&lang=fr. Acesso em: 2 set.2019.

SHNAPPER, Dominique. Communauté des citoyens. Sur l'ídée moderne de nations. Paris: Gallimard, 1994.

SHNAPPER, Dominique;BACHELLER, Christian. Qu'est-ce que la citoyenneté'? Paris: Gallimard, 2000.

Prof. Dr. Antonio Chizzotti Pontifícia Universidade Católica de São Paulo (Brasil) Faculdade de Educação Programa de Pós-Graduação em Educação: Currículo Grupo de Pesquisa Políitica de Educação/Currículo ORCID : https://orcid.org/0000-0002-2752-2330

E-mail: anchizo@uol.com.br Recebido 19 nov. 2019 Aceito 9 dez. 2019 